\title{
AGRICULTURA ORGÂNICA NO NORTE DO PARANÁ: ALTERNATIVA AS IMPOSIÇÕES DO MODELO HEGEMÔNICO DA AGRICULTURA CONVENCIONAL ${ }^{1}$
}

\author{
Margarida Cássia Campos ${ }^{2}$
}

\section{Resumo}

Ser um agricultor orgânico em meio ao padrão hegemônico imposto pela agricultura capitalista é uma tarefa para poucos homens. O agricultor orgânico do Norte do Paraná, onde realizamos nossa pesquisa empírica, encontra-se instalado em um espaço geográfico, onde as formas de produção via agricultura convencional é uma das mais bem sucedidas do Brasil.

Portanto, ao averiguar que havia produtores orgânicos no Norte do Paraná, percebemos uma problemática que poderia ser estudada pela geografia. Como esses poucos, conseguiam se organizar e produzir em um espaço agrário tão adverso? Constatamos, que ao utilizar técnicas de diferentes correntes da agricultura alternativa: Biodinâmica, Biológica, Natural e Agroecológica. Os agricultores orgânicos somam essas técnicas as suas e assim resistem e produzem alimentos livres de agroquímicos, preservam o meio ambiente e não prejudicam sua saúde e da sua família.

Palavras chaves: agricultura orgânica, meio ambiente e modernização da agricultura

\begin{abstract}
Being an organic agriculturist in middle of the hegemonic pattern imposed by the capitalist agriculture is a task for few men.The organic agriculturist of the North of Paraná, where our empirical research took place find himself installed in a geographic space, where the ways of production, through conventional agriculture is one of the most successful in Brazil.Due this fact, while inquiring that there were organic producers in the North of Paraná, we noticed a problem that could be studied by the geography. How these few men could organize themselves and produce in an agrarian space so adverse? We noticed that while using different techniques of the alternative agriculture: Biodynamics, Biological, Natural and Ecological Agriculture. The organic agriculturist sum these techniques to their previous techniques and

\footnotetext{
. Artigo resultante da dissertação de mestrado: Territorialização da Agricultura Orgânica do Norte do Paraná: Preservando o meio ambiente e produzindo alimentos sadios.

2 Doutoranda do curso de pós-graduação em Geografia da Universidade Federal de Santa Catarina e professora temporária da Universidade Estadual de Londrina
} 
then resist and produce food free of agricultural chemistry, preserve the environment and do not harm their health and the health of their families.

Key Words: organic agriculture, environment, Modernization of agriculture

\section{1-Introdução}

O presente trabalho é parte das reflexões realizadas em nossa dissertação de mestrado, cujo objetivo foi compreender como os produtores orgânicos conseguiam se organizar no espaço geográfico do Norte do Paraná, onde o padrão de produção da agricultura capitalista (convencional) é altamente hegemônico.

A fim de alcançar os objetivos realizamos um levantamento bibliográfico sobre o processo de modernização da agricultura no mundo, em especial no Brasil, e suas consequências para o meio ambiente. As correntes ligadas à agricultura alternativa tais como: Biológica, Biodinâmica, Agroecologica, Natural, bem como a Orgânica, também foram contempladas nessa busca bibliográfica.

E finalmente o trabalho empírico, com os agricultores da APOL (Associação dos Agricultores Orgânicos do Norte do Paraná), via aplicação de questionário e entrevistas, com o intuito de verificar como estes conseguiam resistir e produzir em um espaço tão adverso à produção livre de agroquímicos.

\section{2- Modernização da agricultura no mundo}

Segundo Ehlers (1999, p.45), a chamada agricultura moderna surge, entre os séculos XVIII e XIX, quando regiões do oeste europeu intensificaram a utilização de técnicas como: a rotação de culturas com plantas forrageiras (leguminosas) e a associação das atividades agrícolas com a pecuária. Esse período ficou conhecido como a Primeira Revolução Agrícola e, como resultado, foi registrado um aumento na produtividade, amenizando o problema de escassez de alimentos vivenciado pela Europa naquele momento.

As descobertas de fertilizantes minerais, na Segunda Revolução Agrícola, em meados do século XIX, aprofundou o processo de modificação das técnicas de produção, "Num terreno cansado, poucos quilos de adubos químicos podiam fazer aquilo que o pousio levaria anos para conseguir ou que exigiria toneladas de esterco e de esforço humano" (KHATOUNIAN, 2001, p.20). Essas transformações possibilitaram certo distanciamento entre a agricultura e a pecuária, conquistada na Primeira Revolução Agrícola. 
Aliado à adubação química, outras descobertas científicas foram proporcionalmente importantes para a consolidação da agricultura moderna, tais como o melhoramento genético das plantas e os motores a combustão interna.

Logo, a produção agrícola que antes era quase totalmente autossuficiente passa a ser subordinada aos ditames da indústria. Este processo se intensificou ainda mais após a Segunda Guerra Mundial onde armas químicas antes utilizadas em combate são vendidas aos agricultores, com objetivo precípuo de resolverem problemas de pragas, doenças e ervas daninhas em suas plantações. Segundo Khatounian (2001, p. 21):

\begin{abstract}
Posteriormente com a proibição das armas químicas, algumas das moléculas básicas se mostraram eficientes como inseticidas abrindo espaço para que o veio a ser um novo e lucrativo mercado. Embora alguns inseticidas orgânicos já fossem conhecidos há muito tempo, sua expansão resultou sobretudo da confluência do interesse da indústria da guerra com o crescimento do problema das pragas. Num segundo e decisivo passo a agricultura se ligava por um segundo laço como cliente da indústria química.
\end{abstract}

Essa aliança entre a indústria bélica e a agricultura foi sem dúvida uma das mais bem sucedidas ao longo da história do capital.

Grandes nomes contribuíram para as descobertas químicas que revolucionaram a produção agrícola, mas, em especial, o alemão Justus von Liebig (1803-1873), considerado o pai da química agrícola, formulou uma teoria na qual afirmava que a "[...] nutrição mineral das plantas se dá essencialmente por substâncias químicas presentes no solo [...]"' EHLERS, 1999, p.22). Liebig não reconhecia o papel da adubação orgânica na nutrição das plantas, (questionando até o poder fertilizante dos húmus). Foi contestado por Pasteur e outros cientistas. Porém, sua ideia tornou-se uma premissa e a adubação química na agricultura passou a ser difundida não somente na Europa, mas em todo o mundo.

As modernizações nas técnicas de produção não se encerraram após a Segunda Guerra Mundial, pois, no final dos anos de 1960 e início de 1970, houve outra revolução na agricultura mundial denominada "Revolução Verde".

A "Revolução Verde" intensificou a aliança entre agricultura e a engenharia genética e produziu variedades geneticamente melhoradas, adaptadas a solos e climas totalmente diferentes do seu ambiente natural. Esse avanço pode ser considerado como o mais importante nesse período, pois proporcionou aos sistemas agrícolas de quase todos os países rentabilidades nunca vistas. E a partir de então houve recordes e recordes de safras, não somente nos países industrializados, mas também naqueles em desenvolvimento.

Outro fator chave, na expansão desse processo, foi a total participação de organismos internacionais, fomentando políticas de adoção ao pacote tecnológico ofertado pela 
"Revolução Verde", tais como: Banco Mundial, Banco Interamericano de Desenvolvimento (BID), United States Agency for International Development (USAID) a Organização das Nações Unidas para a Agricultura e Alimentação (FAO) e uma efetiva presença dos governos incentivando órgãos de pesquisa e de extensão.

A década de 70 do século passado viu consolidar a transformação na agricultura iniciada no século XVIII. O pacote estava completo. Agora, o agricultor não necessitava mais de um grande contingente de mão-de-obra e nem de grandes quantidades de esterco de animais para realizar a produção em extensas áreas de uma mesma cultura que era ou não adaptada ao solo e ao clima, pois a química e a biotecnologia havia solucionado esse empecilho.

Ao produtor estava disponível uma série de insumos: inseticidas, herbicidas, fungicidas, fertilizantes entre outros. O agricultor perdeu a visão sistêmica e holística da relação solo/planta/homem; a indústria desapropriou o saber individual e o tornou um "racionalista", onde cada problema que surge em sua propriedade poderá ser solucionado a partir do uso de um "frasco de veneno". Dessa forma, a denominada agricultura convencional torna-se hegemônica, hoje difundida mundialmente, cujas consequências, principalmente ambientais, são bastante conhecidas.

\section{3- Algumas considerações sobre o processo de modernização da agricultura brasileira}

A difusão do processo de modernização da agricultura, em alguns países do mundo, foi recebido no Brasil a partir de meados da década de sessenta do século passado, sobretudo durante a década de setenta.

Seguramente o Centro-Sul do Brasil foi a região onde a modernização da agricultura se deu de forma mais acelerada e contínua. Para Graziano da Silva (1981), esse processo ocorreu de forma desigual no território brasileiro, ou seja, nem todas as regiões foram contempladas com novas tecnologias. A modernização foi também seletiva em relação aos produtores, apenas uma pequena parcela, na maioria dos casos, médios e grandes, que cultivava para a exportação teve acesso a crédito agrícola farto após 1965, e modernizou suas propriedades.

Ademais, cabe considerar que o processo de modernização da agricultura no Brasil, solidificou-se a partir da instalação de um parque industrial que atenderia as necessidades de 
produção de tecnologias que seriam empregadas na agricultura e progressivamente instalamse várias indústrias de insumos agrícolas em nosso território.

Em relação a esse processo Graziano da Silva (1981, p.46) observa que:

[...] após se haver consolidado a hegemonia do capital industrial com a industrialização pesada que se deslancha o processo de modernização da agricultura brasileira [...] em poucas palavras no processo de desenvolvimento capitalista brasileiro do pós- guerra, a agricultura se converteu gradativamente num setor subordinado à indústria e por ela transformada

Prosseguindo, Ipardes (1981, p.31) constatou:

O rápido processo de industrialização ocorrido no Brasil a partir de 1955 vai diferenciando o aparelho produtivo industrial e dando origem a novos setores que produzem máquinas e equipamentos agrícolas instala-se a petroquímica, e a química e mineração avançaram rapidamente produzindo corretivos de solos, adubos, defensivos, etc... instala-se a nível nacional um complexo industrial ligado a produção de insumos e máquinas agrícolas, criando condições objetivas para a modernização da agricultura.

Atualmente o processo de modernização ainda continua no espaço agrário brasileiro, pois a cada safra aparecem espécies cada vez mais produtivas com maior rentabilidade por hectare, fruto da mais nova arma da agricultura moderna, ou seja, o melhoramento genético, "filho" da biotecnologia presente em quase todos os institutos de pesquisa agropecuários estatais e particulares, com o intuito de desenvolver espécies mais resistentes a pragas, doenças e ervas daninhas.

A consolidação do processo de modernização da agricultura no Brasil foi impulsionado pela atuação de alguns agentes como: as políticas públicas do Estado brasileiro; institutos de pesquisas e as escolas de agronomia que orientaram o sistema de pesquisa e educação para a difusão do padrão tecnológico da "Revolução Verde" e de várias multinacionais produtoras de insumos agrícolas, que instalaram suas filiais em território nacional com o intuito de ofertar tratores, colhedeiras, plantadeiras, arados, fertilizantes, inseticidas, herbicidas, entre outros. Esses agentes desempenharam papel chave para a completa instalação “do novo produzir" no espaço agrário brasileiro.

\section{4-Utilização de agroquímicos no processo de produção: consequências ambientais e sociais}

Primeiramente é pertinente destacar que esse tipo de indústria é fruto da Segunda Guerra Mundial. 
[...] No decorrer do desenvolvimento de agentes utilizáveis na guerra química, algumas substâncias criadas em laboratório, revelaram, ao que se descobriu efeitos letais para os insetos. A descoberta não ocorreu por acaso, os insetos já havia sendo usados nas experiências que se faziam para testar os agentes químicos de morte para o homem. (CARSON, 1964, p.26)

Depois do fim da Segunda Guerra, tanto os perdedores como os que tiveram êxito adaptaram armas de guerra para a agricultura e passaram a utilizá-las e posteriormente vendêlas como defensivos agrícolas (em especial os inseticidas) aos países pobres com intuito de arrecadar dinheiro para a reconstrução de seu país, com sérios problemas financeiros pósguerra.

O principal ativo do agente laranja o 2,4 D, ainda hoje é utilizado entre nós como arbusticida em pastagens. Culturas adubadas com esterco provenientes de áreas tratadas com esse herbicida podem apresentar sério comprometimento em seu desenvolvimento. Como se sabe o agente laranja foi utilizado pelos Estados Unidos na guerra contra o Vietnã, para desfolhar as florestas, via essa estratégia os americanos detectavam melhor os vietnamitas. Foram usados 76 milhões de litros de herbicidas nesta guerra, em uma área de 2,5 milhões de hectares. A Monsanto foi a principal fornecedora do veneno. Segundo dados, 500 mil crianças nasceram com deformidades causadas pela contaminação com dioxina (componente básico do 2, 4-D). (KHATOUNIAN, 2001, p. 22).

O Brasil, a partir da década de 1960, passou a importar agroquímicos, e agricultores iniciaram sua utilização, via recursos do Sistema Nacional de Crédito Rural. Tais recursos eram ofertados àqueles produtores que se dedicavam à produção em grande escala (monocultura). Assim, torna-se indissociável a união monocultura/ utilização de fertilizantes e defensivos.

[...] A expansão do consumo de fertilizantes nas últimas décadas foi intensa e se deveu a política governamental de subsídios e de juros subsidiados para a sua compra (ambas políticas) funcionaram alternativamente ou conjuntamente durante o período (SORJ, 1980, p. 36)

Outro fator chave nesse processo foi a extensão rural. A utilização de agroquímico era repassada aos agricultores por meio de técnicos.

[...] Os agrônomos da extensão rural reeducaram os agricultores, para que eles esquecessem sua sabedoria. . Os defensivos agrícolas foram cultuados como a salvação; da Humanidade, é o que eles aprendiam nas escolas e faculdades. Quem ousasse a questionar era considerado comunista e atrasado (ZAMBERLAM, 2001, p.25)

Com o endeusamento do uso de agrotóxicos no combate às pragas e consequentemente, o aumento de produtividade, as políticas públicas direcionaram seus recursos para ampliação do uso maciço dos "elixires da morte". 
Em 1975, é criado pelo governo brasileiro o Plano Nacional de Defensivos Agrícolas (PNDA), visando diminuir a dependência de importação destes produtos, pois havia uma preocupação estatal em produzi-los em solo pátrio. Essa medida também visava reduzir os preços dos produtos, já que, após a crise do petróleo de 1973, a importação torna-se muito onerosa.

A referida medida deu um grande incremento à produção nacional que "saltou de 4.000 toneladas em 1964, para 56.300 toneladas, em 1980.” (EHLERS, 1999, p.41).

Essas cifras provam que o espaço agrário brasileiro foi palco de um pacote tecnológico que não somente alterou a forma de produzir, mas também as relações sociais, pois os defensivos substituíram uma grande parcela de mão-de-obra que antes era utilizada na prática de tratos culturais das lavouras, tarefa que é realizada atualmente com êxito pelos herbicidas.

Um dos principais aspectos do uso indiscriminado de agroquímicas diz respeito à problemática ambiental. Vários trabalhos referentes a este tipo de preocupação já foram publicados, destaque para o pioneiro, o livro de Rachel Carson, “Silent Spring”, publicado em 1962. A autora sofreu várias ameaças e perseguições de empresas produtoras de agroquímicos devido às denúncias deste livro.

[...] O que coloca os inseticidas sintéticos em categoria à parte é a enorme potencia biológica. Eles possuem poder imenso não somente de envenenar, mas também de penetrar nos processos mais vitais do organismo, modificando-os em sentido sinistro e, com freqüência em sentido mortal. Assim, como veremos, eles destroem as próprias enzimas cuja função consiste em proteger o corpo contra danos, eles impedem os processos de oxidação de que o corpo recebe a sua energia. Opõem obstáculos para impedir o funcionamento normal de vários órgãos, e podem iniciar, em determinadas células, modificações lentas e irreversíveis que conduzem a enfermidades malignas ( CARSON, 1964, p. 26)

Outro trabalho de suma importância trata-se do livro intitulado O futuro roubado, (1997). Esse livro realiza denúncias sobre os problemas provocados pelo uso indiscriminado de agroquímicos e os malefícios para a saúde humana (inclusive a infertilidade masculina). Os autores destacam que a "Revolução Verde" não erradicou a fome do mundo, somente a aumentou, e provocou sérios problemas que perpetuarão no meio ambiente e na saúde humana por várias gerações.

Ao longo do processo de modernização da agricultura no Brasil, vários problemas ambientais surgiram em decorrência deste pacote tecnológico. A intensa mecanização e o uso indiscriminado de agrotóxicos foram os grandes depredadores do meio ambiente. Estes elementos geraram a destruição de ambientes frágeis, que atualmente se encontram em processo de desertificação. A poluição do solo, a contaminação das águas de superfície e de lençóis freáticos provocaram o fim de algumas espécies e contaminação dos alimentos. 
Para Martins (2000, p.20), a introdução de um elemento estranho na natureza, como os pesticidas, pode acarretar dois tipos de problemas.

[...] 1) embora sejam dirigidas às pragas, os pesticidas podem atacar com maior intensidade seus inimigos naturais, fazendo com que estas pragas se tornem mais poderosas, na medida em que seus inimigos naturais foram seriamente afetados. 2) Ao atacar os inimigos naturais de uma praga , os pesticidas podem gerar a chamada praga "secundária" pois, na medida em que ataca os inimigos naturais de uma espécie que tem potencial de praga, esta, ao ficar livre de seus inimigos naturais, passa a constituir em uma praga.

A falha está em não reconhecer que até as “pragas" são necessárias para a manutenção do equilíbrio nos sistemas agrícolas. Uma das alternativas para combater as "pragas" e doenças na agricultura é a utilização dos inimigos naturais que, além de ser uma técnica simples, é bem mais barata do que o uso de inseticidas, e o mais importante, não causam danos ao meio ambiente. Carson, já em 1962, coloca esta técnica como alternativa ao método de utilização de pesticidas.

Segundo Ganini (1999, p.5), a análise dos dados da FAO- Organizações das Nações Unidas para a Agricultura e Alimentação, aponta o Brasil como uns dos países que mais exagera no uso de pesticidas, principalmente na horticultura. $\mathrm{O}$ documento relata que a média nacional de aplicação de tal substância na horticultura é de 10 mil litros por 1 hectare.

Desta forma, ao intensificar a utilização destes produtos, o agricultor contamina os alimentos, prejudica o meio ambiente, sua saúde e a dos trabalhadores rurais, porque, na maioria das vezes, não usa os equipamentos de proteção adequada, não aplicam de forma correta e nem descarta as embalagens, muitos até as utilizam para outros fins.

Na tabela a seguir pode-se observar: na medida que cresce a venda de agrotóxicos, aumenta o número de intoxicações e óbitos no Brasil.

Tabela 1- Volume de vendas versus número de intoxicações e óbitos no Brasil

\begin{tabular}{l|l|l|l}
\hline Período & Vendas em US\$ milhões & n.de intoxicações & n. de óbitos \\
\hline 1993 & 1.050 & 3.418 & 118 \\
\hline 1994 & 1.404 & 4.763 & 139 \\
\hline 1995 & 1.536 & 4.763 & 139 \\
\hline 1996 & 1.793 & 4.911 & 130 \\
\hline 1997 & 2.161 & 4.759 & 142 \\
\hline Fonte: Folha (03/03/98) apud Ganini (1999, p.5)
\end{tabular}


O emprego de produtos químicos na agricultura não prejudica somente aqueles que os manuseiam ou que trabalham diretamente com a lavoura, mas também podem causar sérios problemas ao solo, cursos d'água, contaminação de alimentos e danos à saúde do consumidor, em geral de natureza respiratória, neurológica, cancerígena, entre outros.

Sabemos que os inseticidas afetam os mecanismos de desencadeamento das funções nervosas, através da interferência na produção dos neurotransmissores-serotoninas e dopaminas. E mais, a diminuição do nível destas substâncias no cérebro está intimamente ligada a casos depressivos.

O Sistema Nacional de Informação Tóxico- Farmacológicas (SINITOX, 2008), da Fundação Oswaldo Cruz registrou em 2003, aproximadamente, 6.000 intoxicações humanas por agrotóxicos. Porém, a Organização Mundial da Saúde e o Ministério da Saúde estimam que mais de 300 mil pessoas se intoxiquem anualmente no Brasil e 5.000 pessoas podem ir a óbito.

Todavia, esses casos não inibem a compra desses produtos, dados mostram que o consumo de agrotóxicos só tem registrado alta. Em 1999, os agricultores brasileiros desembolsaram 2,3 bilhões de dólares na compra dos referidos produtos, em 2000 houve um crescimento de 200 mil dólares e em 2006, as vendas de defensivos agrícolas no Brasil totalizaram US\$ 3,920 bilhões contra US\$ 4,244 bilhões do ano anterior. As culturas que mais utilizam são: soja, milho, arroz, algodão, feijão, café, citrus, hortaliça, batatinha inglesa (SINDAG, 2008)

A legislação brasileira que regula o uso e a fabricação dos agrotóxicos é recente. A Constituição Federal somente tratou especificamente dos defensivos agrícolas em 1989. A lei número 7.802/89 disciplina o uso, a aplicação, o comércio e o transporte dessas substâncias no Brasil. O decreto número 98.816, de 1990, determina que esses produtos só deveriam ser utilizados após orientação de um profissional, no caso, um engenheiro agrônomo.

$\mathrm{O}$ artigo 46 desse decreto determina que o descarte de embalagens dos agrotóxicos deverá obedecer a recomendações técnicas. Em muitos casos, recomenda-se que as embalagens sejam enterradas, o que favorece a contaminação do lençol freático.

Outro agravante em relação ao descaso do governo e da legislação a respeito das normas de utilização do referido produto está nas mudanças da classificação dos agrotóxicos realizadas em 1991. Os venenos de faixa vermelha (altamente tóxicos) de classe I passaram para a faixa azul (pouco tóxico), classe III ou faixa verde (praticamente não tóxico), classe IV. Aliado a isto promoveu um aumento de até $75 \%$ na concentração do princípio ativo das formulações dos agrotóxicos. E mais, o Ministério da Saúde, através da portaria n. 764 de 24/09/98, autorizou resíduos 10 vezes maiores no nível de Glifosato (principio ativo do 
Roundup) na soja transgênica, com o intuito de legalizar o uso maior deste herbicida de acordo com os interesses do fabricante.

Na tabela 3, são listados vários produtos que já foram proibidos em muitos países pela sua toxidez e por causar danos à saúde das pessoas e ao meio ambiente, porém continuam sendo utilizados no Brasil.

Tabela 3-Tipos de Agrotóxicos: efeitos na saúde humana e os países onde são proibidos

\begin{tabular}{|c|c|c|}
\hline Agrotóxico & Efeito à saúde & Países onde são proibidos \\
\hline Aldicarb & Sem antídoto. & $\begin{array}{l}\text { Alguns Estados norte-americanos e de uso fortemente } \\
\text { restrito na Áustria, Filipinas, Holanda e Inglaterra }\end{array}$ \\
\hline Aldrin & $\begin{array}{l}\text { Sem antídoto. Cancerígeno e } \\
\text { mutagênico.. }\end{array}$ & $\begin{array}{l}\text { Completamente proibido na Hungria, Israel, Japão, } \\
\text { Noruega, Suécia, Turquia e Rússia. Proibido o uso } \\
\text { agrícola na Argentina, Bulgária, Canadá, Chipre, } \\
\text { Comunidade Comum Européia, Estados Unidos Filipinas } \\
\text { e Finlândia }\end{array}$ \\
\hline Benomyl & $\begin{array}{l}\text { Sem antídoto. Cancerígeno } \mathrm{e} \\
\text { mutagênico. }\end{array}$ & Proibido na Finlândia e severamente restrito na Suécia. \\
\hline Captafol & Sem antídoto. Cancerígeno. & Proibido na Noruega, Suécia e Alemanha \\
\hline Dimetoano & 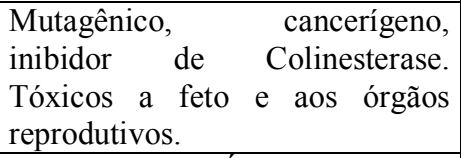 & Sujeitos a severas restrições nos Estados Unidos \\
\hline Dodecacloro & $\begin{array}{l}\text { Sem antídoto. É biocumulado } \\
\text { nas cadeias alimentares e causa } \\
\text { danos prolongados ao meio } \\
\text { ambiente. Cancerígeno. }\end{array}$ & Proibido no Canadá. \\
\hline Endossulfan & Sem antídoto. & $\begin{array}{l}\text { Proibido para uso agrícola na Bulgária e severamente } \\
\text { restrito na Dinamarca, Filipinas, Hungria, Israel e Suécia. }\end{array}$ \\
\hline $\begin{array}{l}\text { Mancozeb, } \\
\text { Maneb, Zineb } \\
\text { e Metiran }\end{array}$ & $\begin{array}{l}\text { Os três primeiros não têm } \\
\text { antídoto. Os quatros são a base } \\
\text { de etileno-bis-ditiocarbamato } \\
\text { (EBTC), sendo suspeito para a } \\
\text { EPA (Agencia de Proteção } \\
\text { Ambiental dos Estados Unidos) } \\
\text { de serem cancerígenos, } \\
\text { teratogênicos e muito perigosos } \\
\text { para a fauna silvestre. }\end{array}$ & O Maneb é proibido na Rússia \\
\hline Paraquat & $\begin{array}{l}\text { Sem antídoto. Causa intoxicação } \\
\text { irreversível. }\end{array}$ & $\begin{array}{l}\text { Proibido na Dinamarca e Suécia. Vendido apenas para } \\
\text { empresas comerciais na Nova Zelândia e nas Filipinas e } \\
\text { sujeito a outras restrições na Finlândia e Turquia }\end{array}$ \\
\hline $\begin{array}{l}\text { Paration } \\
\text { Etílico }\end{array}$ & $\begin{array}{l}\text { Sem antídoto. Alta toxidade e } \\
\text { danos ao meio ambiente. }\end{array}$ & $\begin{array}{l}\text { Proibido na Índia, Japão, Noruega, Suécia, Filipinas e } \\
\text { Turquia. Uso agrícola proibido na Rússia, severas } \\
\text { restrições nos Estados Unidos, Israel e Dinamarca. }\end{array}$ \\
\hline $\begin{array}{l}\text { Paration } \\
\text { Metilíco }\end{array}$ & & $\begin{array}{l}\text { Proibido no Japão e África do Sul, com medidas } \\
\text { restritivas especiais na Hungria. }\end{array}$ \\
\hline
\end{tabular}

Ainda é muito tímida a atuação dos órgãos públicos competentes em relação aos efeitos causados à saúde por esses agrotóxicos no Brasil. Enquanto que em alguns países estes 
produtos são proibidos, os agricultores, o meio ambiente e os consumidores brasileiros se encontram expostos aos efeitos mortíferos de tais agroquímicos.

Outro problema decorrente da agricultura tradicional é o alto grau de energia utilizado. O uso de insumos (fertilizantes, defensivos químicos e herbicidas) e a mecanização trouxeram um elevado aumento na produtividade, porém, com o passar do tempo, esta decaiu e o uso de corretivos se intensificou; mesmo assim, continua em decréscimo. Isto se deve à deteriorização da estrutura do solo, e ao uso maciço de tais substâncias. Portanto, a agricultura convencional dos últimos 30 anos, configura-se como um modelo de produção altamente dependente de recursos energéticos não renováveis, impróprio e caríssimo do ponto de vista ambiental para as gerações futuras.

Outrossim, é evidente que a modernização da agricultura brasileira, além de outras conseqüências, expulsou o homem do campo e, em seguida, causou vários problemas no local de destino desta população, provocou também danos ao meio ambiente e à saúde humana. A Agricultura Orgânica atualmente configura-se como uma forma de produção que reconsidera estes problemas, incentivando o emprego no campo e produzindo alimentos livres de agrotóxicos.

\section{5- Os movimentos ligados à Agricultura Orgânica}

Considera como ecológicos todos os movimentos alternativos à agricultura tradicional, que questionam os problemas causados pelo uso excessivo de agroquímicos na agricultura.

Inicialmente surgiram em alguns países nas décadas de 1920 a 1940, e outros nas décadas subsequentes e ganharam adeptos no decorrer do século XX. Mesmo sendo diferentes em alguns pontos de caráter técnico, todos salientam a preservação dos recursos naturais e a produção de alimentos livres de agrotóxicos.

Esse tipo de agricultura apresentou um grande avanço nos últimos anos, principalmente a orgânica, na medida em que a sociedade passou a se preocupar com a saúde e com o meio ambiente. Para tanto, destaca-se o papel da mídia ao noticiar incidentes relativos à contaminação de alimentos e de agricultores pelo uso excessivo de produtos químicos; o papel do capital em buscar novas formas de reprodução, através da venda do "verde" e "natural". Agrega-se valor nestes alimentos (em tempos de tantas contestações ao modo de produzir de forma convencional), levando aquele que tem um elevado poder aquisitivo a aderir à compra destes produtos. 


\section{1- Agricultura Orgânica}

A Agricultura Orgânica foi criada pelo inglês Sir Albert Howard, em 1905, quando trabalhou na Índia numa estação experimental. Observando os camponeses indianos, ficou intrigado ao perceber que não utilizavam fertilizantes, pesticidas e herbicidas químicos em suas lavouras, porém devolviam aos solos resíduos vegetais e animais devidamente acumulados. Nestas comunidades, tanto as plantas como os animais se desenvolviam de forma sadia, enquanto as plantas e animais da estação experimental (usando os agentes químicos mencionados acima) constantemente eram atacados por uma nova doença. "[...] o fertilizante básico dos indianos era preparado misturando-se excrementos animais com restos de culturas, cinzas, ervas daninhas, o que resultava no compost manure (esterco composto), onde se originou o termo 'composto', hoje corrente [...]” (KHATOUNIAN, 2001, p.26)

Para Howard, o princípio básico para uma vida intensa e rica para as plantas era garantida pela fertilidade do solo, pois, segundo seus ideais, no solo ocorre uma série de processos vivos e dinâmicos à saúde das plantas. (HOWARD, 1943 apud DAROLT, 2002, p.22).

Este movimento, segundo Darolt (2002, p. 22), foi aprimorado pela inglesa Lady Eve Balfour que transformou sua fazenda na Inglaterra em um campo experimental de Agricultura Orgânica. Em 1946, fundou uma entidade denominada Soil Association, publicando diversos documentos onde ressaltava a importância da qualidade dos processos biológicos do solo para a saúde humana, vegetal e animal.

A Agricultura Orgânica ganhou grande repercussão nos Estados Unidos onde, em 1940, Jerome Irving Rodale fundou o Rodale Institute, com a finalidade de realizar pesquisa sobre o assunto. Este mesmo país foi o primeiro a regulamentar e rotular os alimentos de procedência orgânica, mais especificamente os Estados de Oregan, Maine e Califórnia ( EHLERS, 1991, p. 52 a 55)

Para Altieri (2002, p.287), a Agricultura Orgânica:

[...] é um sistema de produção agrícola que evita ou praticamente exclui os fertilizantes e pesticidas sintéticos. Sempre que possível, os insumos de origem externa como agroquímicos e os combustíveis adquiridos no comércio, são substituídos pelos recursos internos, encontrados em suas propriedades.

A Agricultura Orgânica pressupõe uma preocupação intensa com a autonomia do produtor, perante o mercado, no mesmo momento que procura a harmonia entre o meio ambiente e a produção agrícola. A prática deverá ser a menos impactante possível, mesmo 
aceitando que é impossível eliminar todo e qualquer dano ao meio ambiente. Este tipo de produção segue os parâmetros que reduzem ao mínimo o impacto ambiental de forma a não comprometer a produtividade, proporcionando aos agricultores um ambiente socialmente justo e economicamente viável.

Muitos veem, porém, a Agricultura Orgânica como retrógrada, um retorno aos métodos da agricultura praticada antes do processo de modernização. Isto não procede, pois o método de produção orgânica é "uma combinação de técnicas de produção tradicional com tecnologias modernas [...] sementes certificadas, adotam práticas de conservação do solo e da água e as mais recentes inovações na alimentação e manejo animal" (ALTIERI, 2002, P.287)

Várias são as vantagens da Agricultura Orgânica em relação à Convencional. Em primeiro lugar todos os agricultores orgânicos ressaltam que a diminuição de custo de produção fica em torno de $30 \%$ por não utilizarem fertilizantes, herbicidas, inseticidas químicos. Em segundo lugar, destacam o contentamento dos agricultores ao falarem de sua propriedade com orgulho de ser um local de preservação ambiental onde se realiza a conservação do solo, a preservação das matas de galeria e, sobretudo, a produção de alimentos livres de resíduos químicos. Em terceiro lugar, cabe ressaltar a oportunidade que estes agricultores estão oferecendo à sociedade de adquirirem produtos mais sadios para seus filhos.

Hoje, a Agricultura Orgânica constitui-se em uma forma de produzir que abrange todas as outras correntes alternativas à agricultura convencional; se o alimento for simplesmente livre de agroquímicos muitos o consideram orgânico, mas, como se viu, o alimento orgânico possui suas regras de produção, que não se restringe somente no não uso do referido produto.

Segundo Darolt (2002), o termo Agricultura Alternativa, Agroecologia não constituem uma corrente ou uma filosofia bem definida, apenas serve para reunir as correntes que se diferenciam da Agricultura Convencional. Porém, a Agricultura Sustentável é um termo bastante desgastado por falta de precisão e pela forma que vem sendo utilizada, sendo que a maioria dos autores que utiliza a coloca como uma agricultura durável a longo tempo, mas não elucida como seria esta agricultura.

Não obstante, atualmente a Agricultura Orgânica aparece como sendo o coletivo de várias outras correntes. Ao longo de 80 anos desde o advento da primeira escola de agricultura alternativa ao modelo convencional (a Agricultura Biodinâmica); vários métodos de produção, forma de atuação junto ao produtor, certificação, produtos agrícolas para atender produtores, regras de produção, teorias, enfim, técnicas agrícolas de várias correntes 
contribuíram para formular o método de produção da Agricultura Orgânica hoje ( ver figura 1).

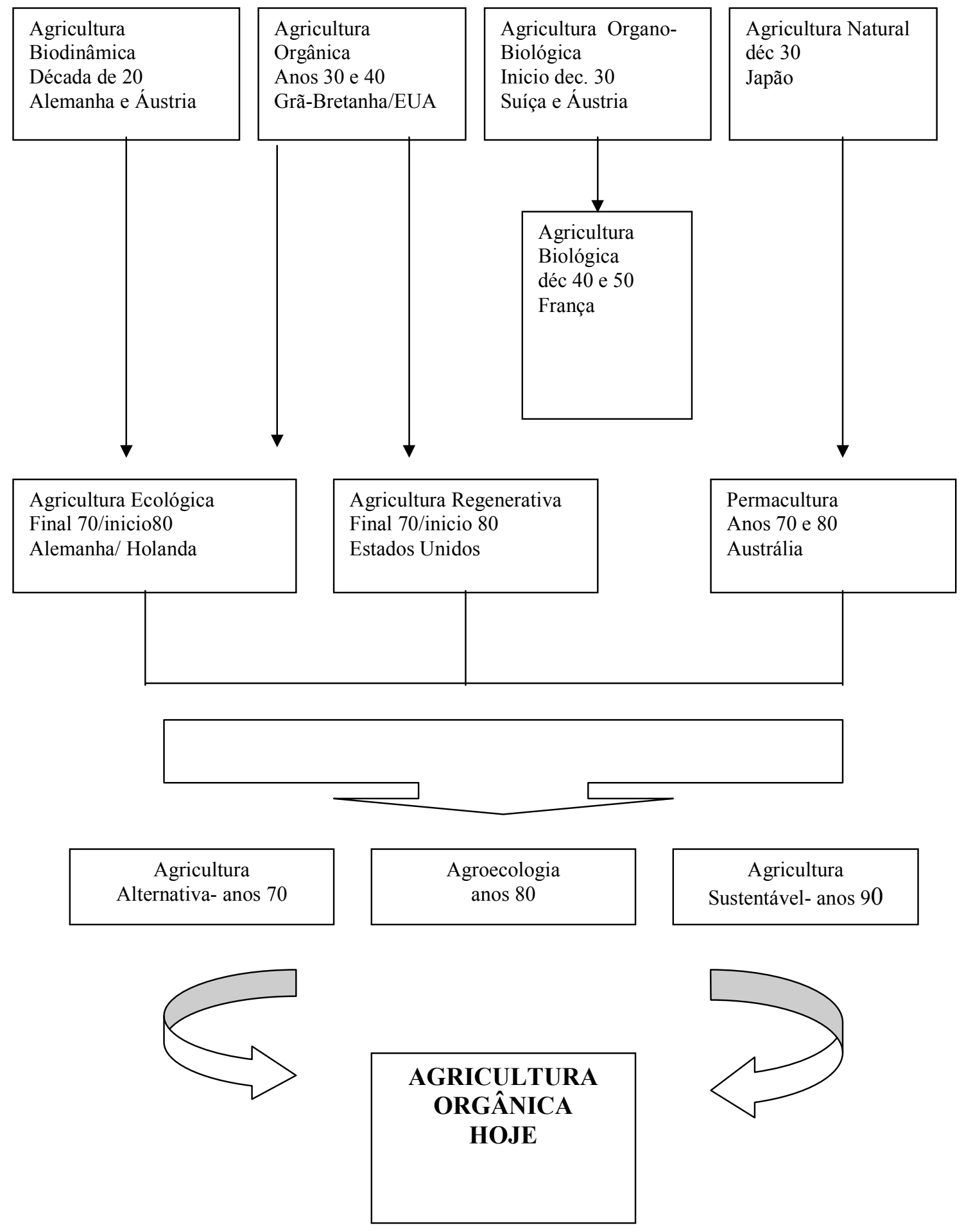

Figuras 1- Principais correntes ligadas ao movimento orgânico

Fonte: Darolt (2002, p.19), adaptado por Margarida Cássia Campos 
5.2- Agricultura Orgânica no Norte do Paraná

Os produtores orgânicos da região de Londrina passaram pelo processo de modernização da agricultura que ocorreu no Estado em meados da década de 1960 e início de 1970.

Em análise ao Censo Agropecuário do Brasil e do Paraná de 1970 a 1996, Campos (2004) constatou que o processo de concentração fundiária, que ocorreu em diversas áreas do Brasil e intensificou-se após os anos 1970 do século passado, sucedeu ao período de introdução de novas técnicas na agricultura, possibilitando assim o desenvolvimento de culturas de caráter comercial que atendia a exportação, sendo viável economicamente apenas em áreas de grande extensão. $\mathrm{Na}$ escala de análise do Estado do Paraná a estrutura fundiária, dentre os pequenos estabelecimentos ( estrato de menos de 10 hectares), sofreu uma redução em 26 anos de $47.63 \%$, em unidades absolutas de 140.652 estabelecimentos, portanto seguiu a lógica do que aconteceu no Brasil nesse período, ou seja, os incentivos de créditos agrícolas para o plantio de safras que atendessem o mercado externo beneficiou em especial o grande proprietário, e este, por sua vez, expandiu sua área ao longo dessas duas décadas e meia, via incorporação da pequena. Observa-se, ainda, que o número total de estabelecimentos agrários paranaenses sofreu uma redução de 33,29\% de 1970 a 1995/96, o que evidencia maior concentração fundiária no Estado.

Em relação ao êxodo rural ocorrido em vários espaços do Brasil, e especialmente no Norte do Paraná, vários foram os fatores, porém, dentre eles, destaque a introdução de máquinas agrícolas, o uso intensivo de insumos e a substituição de culturas entre outros.

$\mathrm{Na}$ análise dos dados que se referem ao efetivo da população rural e urbana brasileira, a mesma autora observa um decréscimo da população rural. Em 1970, esta contava com 44,1\% do total; em 1980 e representava 32,4\%; e, em 1991, 24,53\% e no último Censo apenas 18,8\%. Uma redução em 30 anos de 25,3\%(em dados absolutos de 9.261 .334 pessoas). Enquanto a população urbana registrou altos índices de crescimento, em 1970, 55,9\% e, em $2000,81,2 \%$ do total populacional brasileiro residia na zona considerada urbana.

Sobre o êxodo rural no Paraná Fleischfresser pontua (1988, p.21):

[...] Esse movimento que eclodiu na década de 70, já se encontrava em estado latente a partir de segundo qüinqüênio dos anos 60 , devido a erradicação dos cafezais. Só que neste período, a população excedente dos cafezais localizados no Norte do Paraná se deslocava em direção as " fronteiras agrícolas" no Estado. Entretanto, nos anos de 70, quando gradativamente se esgota, concomitante ao processo e intensificação no uso da modernização tecnológica (caracteristicamente 
poupadora de mão-de-obra) e a substituição de culturas, agora não mais somente o café, mas também alimentares, por soja e pecuária, verifica-se uma notável evasão da população residente no meio rural.

No caso especifico do Norte do Paraná, como salienta a autora acima, áreas antes ocupadas por cafezais, foram substituídas por culturas que exigiam pouca mão-de-obra e intensa mecanização, utilizando-se de fertilizantes, herbicidas e inseticidas.

Por fim, para melhor entendermos a história de produção e a transformação destes produtores convencionais, que passaram pelo processo descrito acima em orgânicos, dividimos os 12 entrevistados em 2 grupos:

$1^{\circ}$ grupo: Dois produtores: situados no município de Londrina, são "neo-rurais", ou seja, nunca tiveram contato com a agricultura e há cerca de um ano compraram um estabelecimento para produzir alimentos orgânicos. É importante salientar que já consumiam alimentos orgânicos há mais de cinco anos. Estes não possuem nenhuma história de produção agrícola, pois sempre viveram na zona urbana e as propriedades ainda estão em fase de investimento.

$2^{\circ}$ grupo: No restante dos dez produtores, três não vivem exclusivamente da renda agrícola, mas possuem longa experiência nesse ramo; como podemos observar, esse grupo resistiu à modernização da agricultura. Muitos absorveram o pacote da "Revolução Verde", outros ficaram à margem, mas resolveram nos últimos anos produzir de maneira diferenciada. E no campo consta que esse era o principal entrave, porque após absorver os novos insumos agrícolas; como deixar de produzir sem a maioria deles (refiro-me aos inseticidas, herbicidas e fertilizantes)?

Nas entrevistas procuramos obter informações sobre quais as técnicas de produção orgânica eles utilizam durante o cultivo, bem como as ideias e os conceitos que seguem para produzir organicamente os alimentos, com o objetivo de averiguar como esse "novo" agricultor está se adequando à produção orgânica. E concluímos que, o produtor orgânico vinculado a APOL (Associação dos Produtores Orgânicos do Norte do Paraná), para resistir e produzir em um espaço tão adverso, mescla vários procedimentos que não são genuinamente da filosofia de produção orgânica. Entre as correntes que possui maior influencia nos produtores orgânicos da região de Londrina estão: Agricultura Biodinâmica, Agricultura Biológica, Agricultura Natural e a Agroecologia.

Para elucidar as citações feitas acima destacamos algumas conclusões:

$\checkmark$ No caso da certificação dos produtos orgânicos, encontram-se três instituições atuantes no Paraná que certificam produtos orgânicos; a Rede Ecovida (originada de uma 
proposta Agroecologia), IBD-Instituto Biodinâmico- (Agricultura Biodinâmica) e Certificadora Mokiti Okada (Agricultura Natural). São certificadoras que não se originaram da filosofia orgânica, mas sim, de outras correntes, porém certifica alimentos orgânicos.

$\checkmark \mathrm{Na}$ região de Londrina, o agrônomo da Fundação Mokiti Okada, Gilberto Shingo oferece assistência técnica a vários produtores orgânicos e comercializa o EM (micronutrientes efetivos), um tipo de insumo biológico para os produtores orgânicos, desenvolvido no Centro de Pesquisa de Agricultura Natural. O referido agrônomo também oferece assistência junto aos produtores de Agricultura Orgânica e Natural. Há também alguns produtores de orgânicos na região de Londrina que iniciaram a produção através de incentivo da Igreja Messiânica, do qual são membros.

$\checkmark$ Existem algumas técnicas defendidas pela Agricultura Natural que os produtores Orgânicos utilizam tais como: rotação de culturas, uso de adubos verdes, emprego de composto e uso de cobertura morta (resto vegetais) sobre o solo. No que se refere ao controle de pragas e doenças aconselha-se a manutenção das características naturais do ambiente e o emprego de inimigos naturais para combatê-las, entre outras técnicas.

$\checkmark$ O IBD oferece aos produtores da APOL (Associação Produtores Orgânicos de Londrina) o calendário astral, onde eles podem consultar qual o melhor dia de plantio e colheita de várias culturas. O presidente da APOL, Lauro Okamura afirma que o consulta regularmente, inclusive deixa-o fixado na parede da sala. Da Agricultura Biodinâmica os produtores utilizam também os aditivos biodinâmicos (insumo biológico).

$\checkmark$ A autonomia do produtor perante o processo de comercialização, proteção ambiental e qualidade biológica dos alimentos e a defesa de ideias que pregam que o solo deve estar bem nutrido para que a planta resista aos ataques das pragas e às doenças (teoria da trofobiose); princípios defendidos por Hans Peter Muller, que sistematizou a corrente da Agricultura Biológica na década de 1930, após estudos de fertilidade do solo e microbiologia. E verificamos que esses pressupostos defendidos pela Agricultura Biológica são difundidos para os agricultores, via os técnicos que oferecem assistência.

Baseado nos exemplos acima se observa que os produtores orgânicos atualmente utilizam os mais diversos métodos, provenientes de várias correntes da agricultura alternativa à convencional, não existindo um agricultor autêntico que é especificamente orgânico. O panorama é muito positivo, pois estes agricultores não estão presos às amarras de uma única 
corrente e podem utilizar em sua propriedade métodos de produção de outras, conforme as peculiaridades da região. Por exemplo, a Agroecologia defende uma relação muito estreita entre homem e natureza, de respeito e ética de trabalho, beneficiando os aspectos ecológicos, econômicos, sociais e culturais. Esses princípios também aparecem nas falas dos produtores orgânicos da APOL.

Constatamos também que o agricultor orgânico da APOL concebe a agricultura como sendo um organismo que depende da interação entre a produção vegetal e a animal, o respeito ao ciclo natural de cada cultura. E para por em prática tais concepções utiliza dos aditivos biodinâmicos (composto líquido elaborado a partir de substâncias minerais, vegetais e animais, altamente diluídas) da Agricultura Biodinâmica com o intuito de reativar as forças vitais da natureza e estimular o crescimento das plantas, segundo princípios homeopáticos.

E também fazem uso de adubos verdes, cerca viva, proteção da fauna e flora circundante, entre outros. Segundo Ehlers (1999) tais cuidados são para garantir o desenvolvimento de uma agricultura onde solo/planta/ambiente convivam de forma harmoniosa.

Mokiti Okada filósofo japonês, em 1935, criou a Igreja Messiânica em seu país, pregava a harmonia entre as atividades agrícolas e a natureza, de forma que a primeira não destruísse a segunda no decorrer do processo de produção dos alimentos. Estes alimentos deveriam ser o mais saudável possível dispensando o uso de pesticidas e inseticidas, enfim quaisquer agentes químicos; ao se alimentar desses alimentos o corpo seria purificado e automaticamente a alma. Londrina possui uma filial do Centro de Pesquisa Mokiti Okada, sendo mais próxima dos produtores do que o IBD (Botucatu-SP), portanto, muitos usam produtos da Agricultura Natural e assistência do agrônomo da referida instituição.

Concluímos, portanto, que o agricultor orgânico da região estudada demonstra ser um homem sábio, ou seja, possui um relativo conhecimento da sistemática de sua propriedade e das práticas possíveis a serem utilizadas naquele espaço, o que o diferencia do produtor convencional. Como se pode notar, para que o produtor orgânico tenha relativo êxito precisa ser "um sujeito de vanguarda".

\section{6-Considerações Finais}

O modelo de agricultura convencional, baseado no uso intensivo de agroquímicos, demonstra sua fragilidade do ponto de vista ambiental, além de ser uma forma de produção que prejudica a saúde não somente dos consumidores, mas do próprio agricultor. 
A Agricultura Orgânica, no Norte do Paraná aparece como alternativa viável para os pequenos produtores, principalmente aqueles que foram excluídos da "Revolução Verde" e também aqueles que se modernizaram, porém, ideologicamente não concordam com muitas técnicas de produção que utilizam e sentem que a sua saúde é prejudicada.

A todos esses o "produzir organicamente" seduz; e aparece como um modelo de resistência às formas de produção hegemônica da agricultura capitalista.

\section{REFERÊNCIAS BIBLIOGRÁFICAS}

ALTIERI, Miguel. Agroecologia: bases científicas para uma agricultura sustentável. Guaíba: AS-PTA, 2002

CARSON, Rachel. Primavera Silenciosa. São Paulo: Edições Melhoramentos. 1964.

CAMPOS, M. Territorialização da Agricultura Orgânica no Norte do Paraná: preservando o meio ambiente e produzindo alimentos sadios. 2004 ( dissertação de mestrado). Universidade Estadual de Londrina- UEL, Londrina.

DAROLT, Moacir R. Agricultura Orgânica: Inventando o Futuro. Londrina: IAPAR, 2002.

EHLERS, Eduardo. Agricultura Sustentável: origens e perspectivas de um novo paradigma. Guaíba: Editora Agropecuária, 1999.

FERnANDES, G. B. et al. 1a Jornada Paranaense de Agroecologia: Terra livre de transgênicos e sem agrotóxicos. União da Vitória: AS-PTA/PR, abril/2002.

FLEISCHFRESSER,Vanessa. Modernização tecnológica da agricultura. Curitiba: Livraria Chain, 1988

GANINI, J. M. M. \& ALVIM. M. I. S. A. Novos Métodos de Cultivo na Agricultura: Agricultura Orgânica. In: CONGRESSO BRASILEIRO DE ECONOMIA E SOCIOLOGIA RURAL, 37., 1999, Foz do Iguaçu. Anais... Foz do Iguaçu: SOBER, 1999. p. 153-172.

GRAZIANO da SILVA, José (cood). Estrutura agrária e produção de subsistência na agricultura brasileira. São Paulo: HUCITEC, 1981.

IPARDES. O Paraná: economia e sociedade. Curitiba. 1981.

KHATOUNIAN, C. A. A reconstrução ecológica da agricultura. Botucatu, SP: Agroecologia, 2001.

MARTINS, P. R. Inovação tecnológica, meio ambiente e sociedade: o caso dos alimentos transgênicos. In: CONGRESSO BRASILEIRO DE ECONOMIA E SOCIOLOGIA RURAL, 38., 2000, Rio de Janeiro, Anais... Campinas: UNICAMP/IRSA/SOBER, 2000. 
SINDAG. Consumo de defensivos agrícola. Disponível em: www.sindag.com.br, consultado em 23 mai. 2008.

SINITOX. Dados sobre agrotóxico. Disponível em: http://www.fiocruz.br/sinitox/agrotoxicos/tabelas casos/serie historicas.htm. Acessado em 25 jun. 2008.

SORJ, B. Estado e Classes Sociais na Agricultura Brasileira. Rio de Janeiro: Zahar, 1980.

ZAMBERLAM, Jurandir \& FRONCHETI, Alceu. Agricultura Ecológica: Preservação do pequeno agricultor e do meio ambiente. Petrópolis: Vozes, 2001.

ZANINI, J. B. Parcerias: Potencialidades e Entraves para o Desenvolvimento do Pólo de Agroecologia do Litoral Paranaense. In: ANAIS DO SEMINÁRIO DO I CURSO DE ESPECIALIZAÇÃO EM DESENVOLVIMENTO RURAL, 1., Pato Branco, Anais... Pato Branco: CEFET-PR/CEPAD/IMPREDEL, 2003. v.1, p.95-111. 